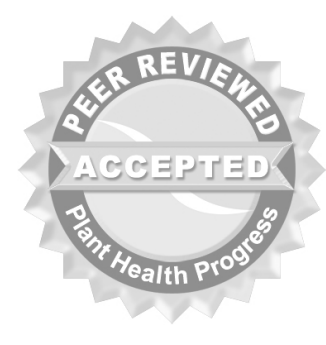

(C) 2012 Plant Management Network.

Accepted for publication 1 May 2012. Published 18 June 2012.

\title{
Effect of Geosmithia morbida Isolate and Temperature on Canker Development in Black Walnut
}

\author{
Emily Freeland, Former Graduate Student, Whitney Cranshaw, \\ Professor, and Ned Tisserat, Professor, Department of \\ Bioagricultural Sciences and Pest Management, Colorado State \\ University, Fort Collins, CO 80523-1177
}

Corresponding author: Ned Tisserat. ned.tisserat@colostate.edu

Freeland, E., Cranshaw, W., and Tisserat, N. 2012. Effect of Geosmithia morbida isolate and temperature on canker development in black walnut. Online. Plant Health Progress doi:10.1094/PHP-2012-0618-01-RS.

\begin{abstract}
Thousand cankers disease of black walnut (Juglans nigra) is the result of aggressive feeding by the walnut twig beetle (Pityophthorus juglandis) and extensive cankering around beetle galleries caused by the fungus Geosmithia morbida. We developed a consistent, reproducible inoculation technique to screen black walnut trees for their reaction to canker development following inoculation with G. morbida. Canker areas in one-year-old trees were not affected by the location on the stem that inoculations were made. Differences in aggressiveness of G. morbida isolates, representing different rDNA ITS haplotype groups, to black walnut were observed in some experiments. However, these differences were small and evidence indicates that a single, highly aggressive haplotype is not responsible for the current TCD epidemic. Cankers formed in black walnut at all temperatures tested, but they were consistently smaller at $32 / 20^{\circ} \mathrm{C}$ day/night temperatures compared to $25 / 20^{\circ} \mathrm{C}$. Although G. morbida is thermotolerant, higher temperatures may not enhance canker development.
\end{abstract}

\section{Introduction}

Thousand cankers disease (TCD) of black walnut (Juglans nigra) is the result of aggressive feeding by the walnut twig beetle (WTB) (Pityophthorus juglandis) and extensive cankering caused by the associated fungal pathogen Geosmithia morbida $(6,12)$. The disease is widespread in black walnut in the western United States (13) and more recently has been confirmed in Tennessee $(4,5)$, Virginia (15), and Pennsylvania (9). TCD now is well established in the native range of black walnut and poses a serious threat to this species.

The WTB was first collected in 1896 in New Mexico (2) in Arizona walnut ( $J$. major) and this has led to speculation that this species may be the native host for the beetle and fungus. Geosmithia morbida has been isolated from WTB galleries in Arizona walnut throughout its northern range in Arizona and New Mexico. In this species, the fungus causes very small cankers in the phloem and is not associated with major dieback or mortality (14). The WTB also has been reported in the native southern California (J. californica) and northern California (J. hindsii) walnuts as well as the introduced Persian walnut (J. regia) in California. (10). The susceptibility of the these walnut species to G. morbida is variable based on field observations and greenhouse inoculation studies, although none are as susceptible as black walnut (14).

Geosmithia morbida is genetically complex, with multiple haplotypes occurring even within the same tree $(3,6)$. There is apparently no correlation between haplotype and the host or geographic region from which the fungus was isolated (3). It is not known if there is a link between diversity within $G$. morbida and its aggressiveness in different genetic backgrounds of black walnut. For example, it is possible that G. morbida haplotypes unique to Arizona walnut may differ in aggressiveness in other hosts. Haplotype and genetic diversity of neutral markers have been shown to correlate to virulence 
differences in different fungi $(7,8,11)$. These factors could influence the current spread of the disease, disease movement, and disease management strategies.

TCD was first observed in Colorado following severe heat and drought conditions in the early 2000 (12). Thus, high temperatures may have played a role in the current epidemic. Geosmithia morbida is thermotolerant with optimal growth at $31^{\circ} \mathrm{C}$ and limited growth at $41^{\circ} \mathrm{C}(6)$, but the interaction between canker development and temperature is unknown.

We conducted several studies to look at interactions between temperature, genetic background of black walnut trees, and G. morbida isolates collected from different hosts and locations on canker development.

\section{Geosmithia morbida Isolates}

One-year-old black walnut trees representing three maternal, half-sibling families (119, 135, and 288) were obtained from Purdue University (Jim McKenna, Hardwood Tree Improvement and Regeneration Center, USDA Forest Service, Purdue University, West Lafayette, IN) in May 2009. Trees were placed in pots containing a soilless mix and maintained in the greenhouse at temperatures between $20^{\circ} \mathrm{C}$ and $26^{\circ} \mathrm{C}$ with $70 \%$ relative humidity. In October 2009, six 3-mm-diameter holes were punched into the bark to the xylem in six trees from each family. The bark plugs were removed and replaced with plugs of sterile half-strength potato dextrose agar (PDA) of a similar size, or PDA plugs colonized by Aspergillus niger or G. morbida isolates 1217 and 1274

(representing rDNA ITS haplotype group 1), 1218 (group 5), and 1271 (group 3). Aspergillus niger was commonly isolated from macerated bark tissue and was included in these experiments as a second control. Haplotype group designations were in accordance with Freeland (3) and all isolates were originally collected from black walnut in Colorado. The six inoculation sites on each tree were spaced approximately 10 to $15 \mathrm{~cm}$ apart along the stem with isolates arranged in a Latin square design to test the effect of stem position on canker development. Inoculation sites were sealed with Parafilm. The Parafilm was removed from wounds after three weeks and after six weeks the stems were harvested and the outer bark was removed to expose phloem discoloration associated with the cankers (Fig. 1). Trees were photographed and canker areas were determined using ImageJ software (National Institutes of Health, Research Services Branch, Bethesda, MD) (1). Data analysis of canker area was performed using SAS software (SAS Institute Inc., Cary, NC, USA). Inoculations were repeated in May 2010 on other trees from the same families, and using the same experimental design with the exception that isolate 1234 (representing haplotype 7 and collected from Arizona walnut in Arizona) was substituted for isolate 1274 .
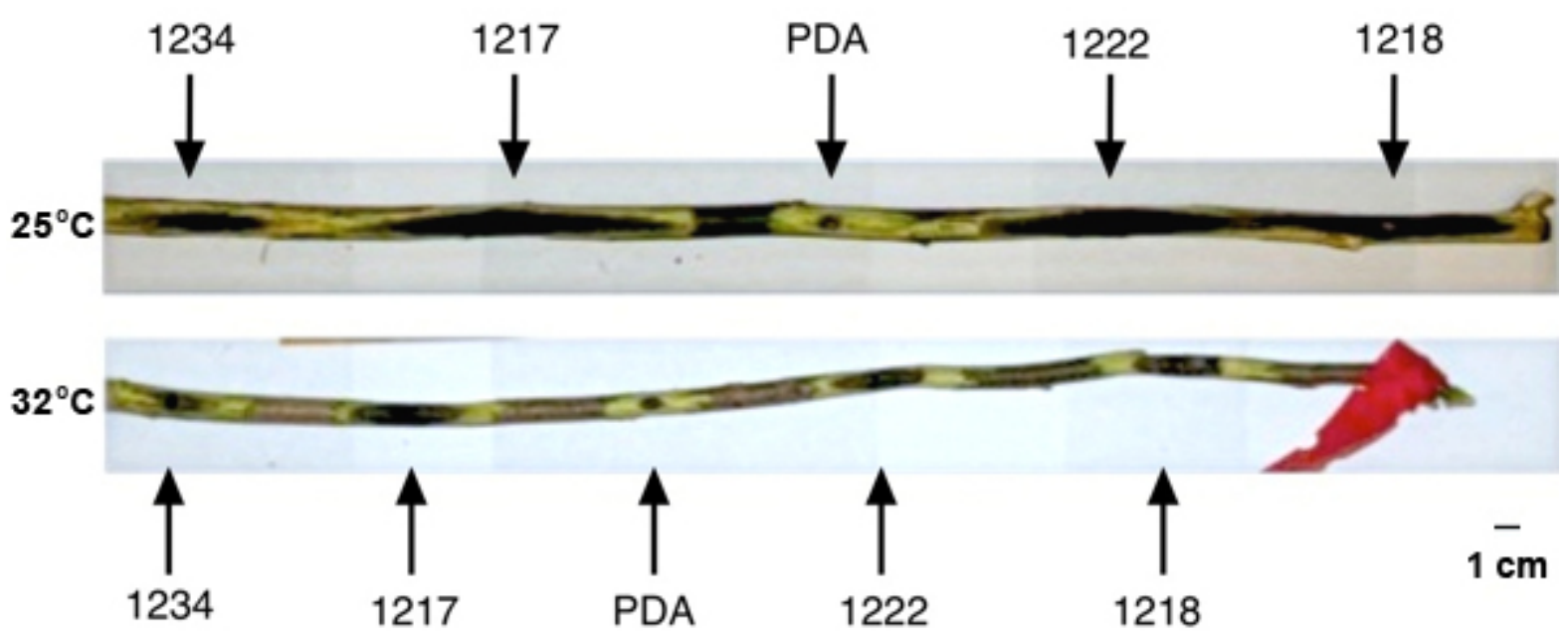

Fig. 1. Canker formation in black walnut (family OSU295) six weeks after inoculation with four isolates of Geosmithia morbida, representing four rDNA ITS haplotypes at $25 / 20^{\circ} \mathrm{C}$ and $32 / 20^{\circ} \mathrm{C}$ day/night temperatures, in August 2010. 
Canker size was not affected $(P>0.10)$ by stem position in the two experiments. In both experiments sterile PDA plugs and $A$. niger produced smaller $(P<0.05)$ areas of phloem discoloration than all the G. morbida isolates. There were no differences $(P>0.10)$ in canker areas among G. morbida isolates tested in October 2009. However, in May 2010 isolate 1234 produced smaller $(P<0.05)$ cankers than isolate 1218 (Fig. 2). Trees in family 135 had smaller $(P<0.05)$ cankers than walnuts belonging to the other two families in October, but differences among families weren't observed when the experiment was repeated (Fig. 3).

\section{October 2009}

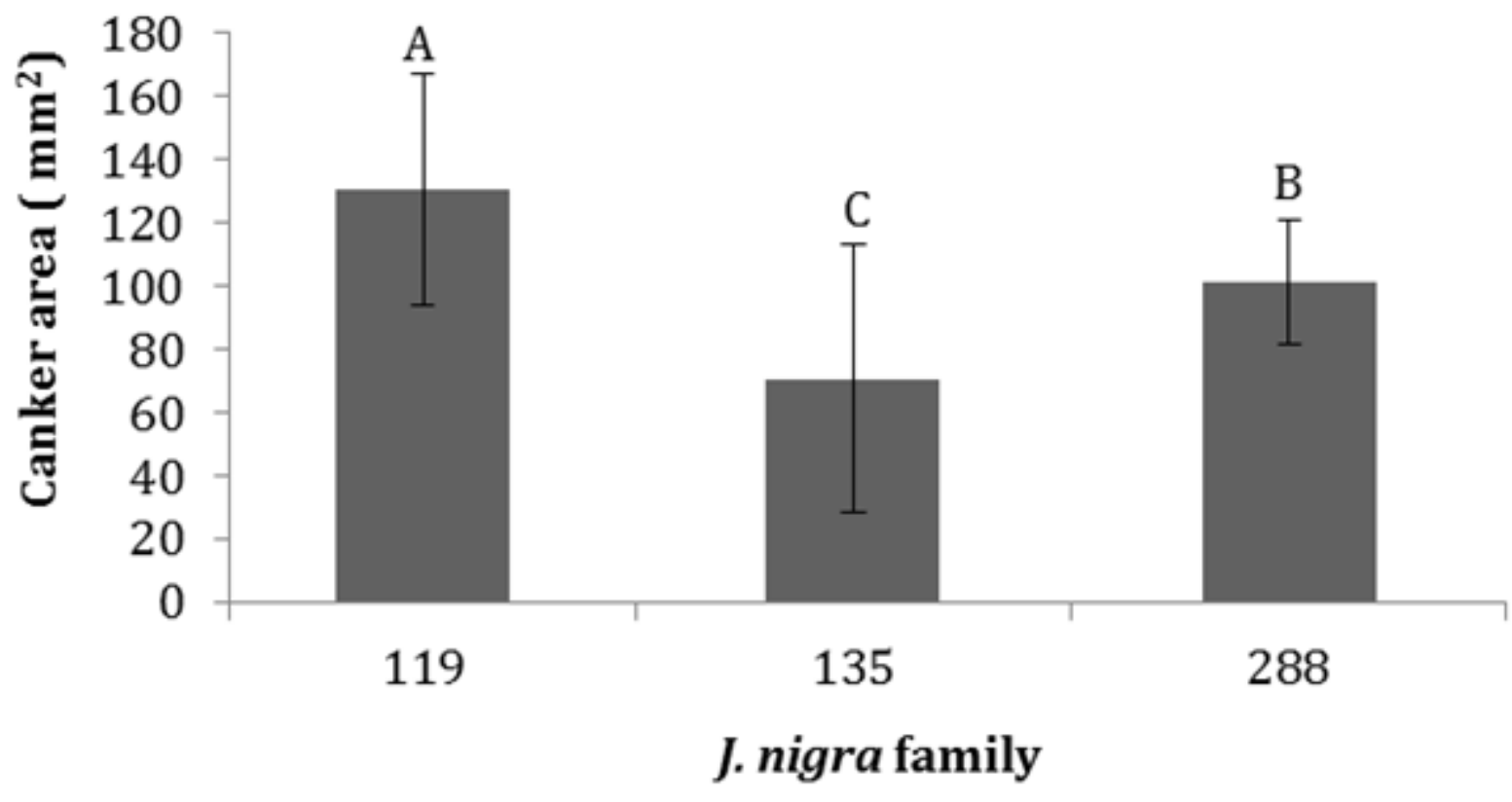

Fig. 2. Average canker area in black walnut half-sibling families following inoculation with four isolates of Geosmithia morbida, representing three rDNA ITS haplotypes, in the greenhouse in October 2009. Values were averaged over four $G$. morbida isolates. Means not followed by the same letter are different $(P=0.05)$ using Tukey HSD adjustment for multiple comparisons. Bars represent standard deviations. 


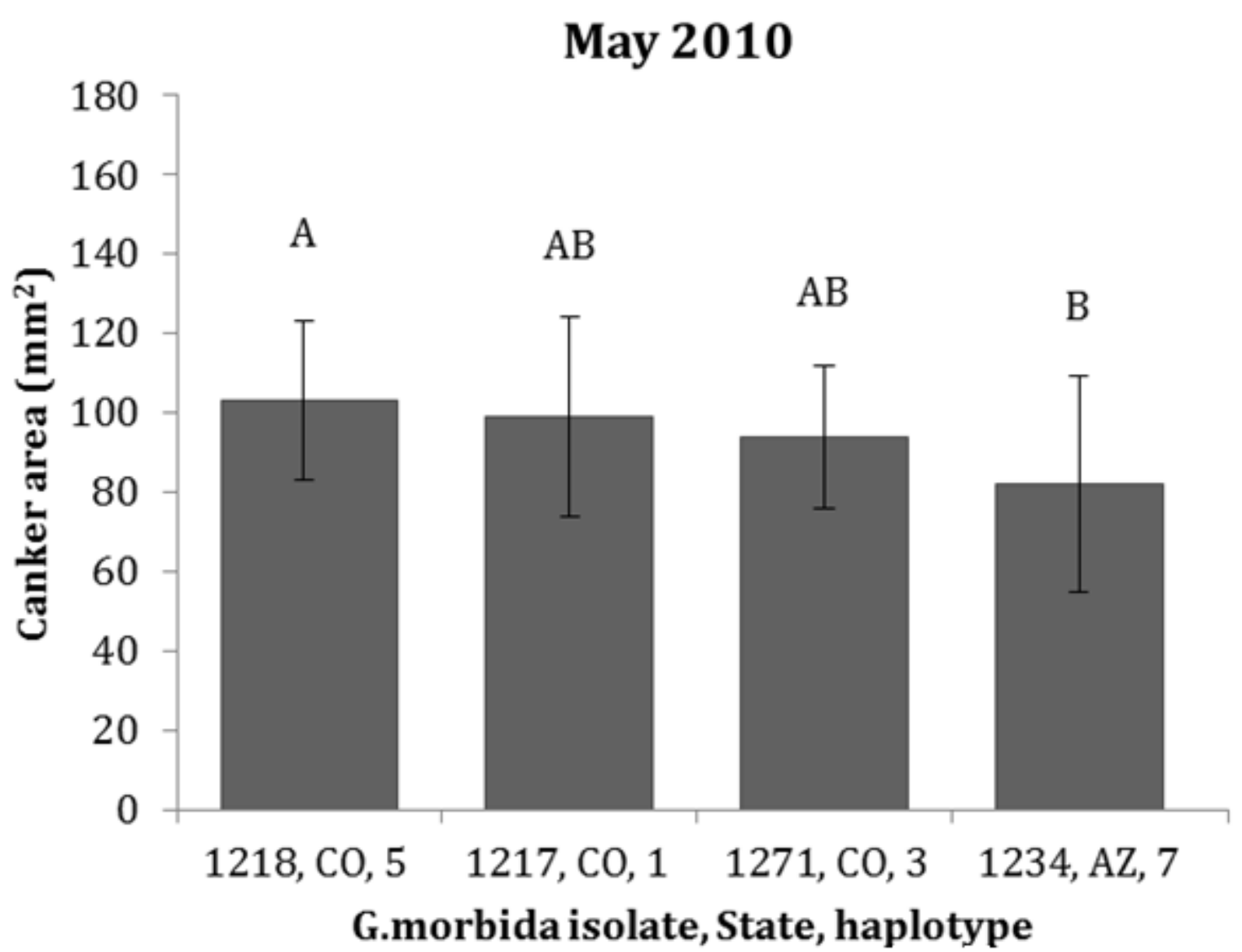

Fig. 3. Average canker area in black walnut trees following inoculation with four Geosmithia morbida isolates representing different rDNA ITS haplotypes, under greenhouse conditions in May 2010. Means not followed by the same letter are different $(P=0.05)$ using Tukey HSD adjustment for multiple comparisons. Values were averaged over three black walnut families. Bars represent standard deviations.

\section{Temperature}

One-year-old, bare-rooted, half-sibling trees representing three black walnut families were placed in pots and maintained in the greenhouse as previously described. In June 2010, five trees each in family OSU1 were placed in one of two growth chambers. Both chambers were set at a day/night cycle of $16 / 8 \mathrm{~h}$, respectively, with a night temperature of $20^{\circ} \mathrm{C}$. The daytime temperatures of the two chambers were maintained at $25^{\circ} \mathrm{C}$ and $32^{\circ} \mathrm{C}$, respectively. Trees were acclimated in growth chambers over a 10 day period and then inoculated with isolates 1217, 1218, 1234, and 1222 (representing haplotype 4 and collected from Persian walnut in Utah) in a Latin square design (isolate position on stem) as previously described. The experiment was repeated in August 2010 with halfsiblings representing family OSU 295 and in October with trees from family Green 280.

In another series of temperature experiments, potted, one-year-old, openpollinated black walnut trees (Kansas State Forest Service, Manhattan KS) were placed in growth chambers at either a constant $20^{\circ} \mathrm{C}$ or at $25 / 22.5^{\circ} \mathrm{C}(12-\mathrm{h}$ day/night cycle) for 10 days prior to inoculation. Trees were inoculated with $G$. morbida isolates 1217 and 1218 as previously described. Since previous experiments indicated that there was no stem position effect on canker development, isolate 1217 was always placed in the bottom and 1218 in the top position of stem wounds. Stems were harvested and canker areas determined after six weeks. The experiment was repeated, except that temperatures in the two growth chambers remained a constant $20^{\circ} \mathrm{C}$ and $25^{\circ} \mathrm{C}$ (12-h day/night cycle) for the duration of the experiment. 
There were no differences $(P>0.10)$ in canker area based on stem position in any of the experiments. Canker areas varied among the three walnut families $(P<0.001)$ and the experiments were therefore analyzed separately. In each experiment, canker areas were larger $(P<0.05)$ when trees were incubated at $25 / 20^{\circ} \mathrm{C}$ day/night compared to $32 / 20^{\circ} \mathrm{C}$. In family OSU 1 , there were no differences in canker areas among G. morbida isolates but in OSU 295, cankers produced by isolate 1234 were smaller $(P<0.05)$ at both temperatures. In family Green 280 , there was an interaction $(P=0.01)$ between temperature and isolate. At $25 / 20^{\circ} \mathrm{C}$ isolate 1218 caused larger cankers than other isolates whereas at $32 / 20^{\circ} \mathrm{C}$ cankers caused by 1218 were larger than those of isolates 1222 and 1217, but not 1234 (Fig. 4). In a second set of experiments, canker area was larger at a day/night temperature of $25 / 22.5^{\circ} \mathrm{C}$ compared to a constant $20^{\circ}$ $\mathrm{C}$ (Fig. 5). No differences were found between isolate 1217 and 1218. In the second experiment, no differences in canker size were found between isolates or the constant incubation temperatures of $20^{\circ} \mathrm{C}$ and $25^{\circ} \mathrm{C}$. 


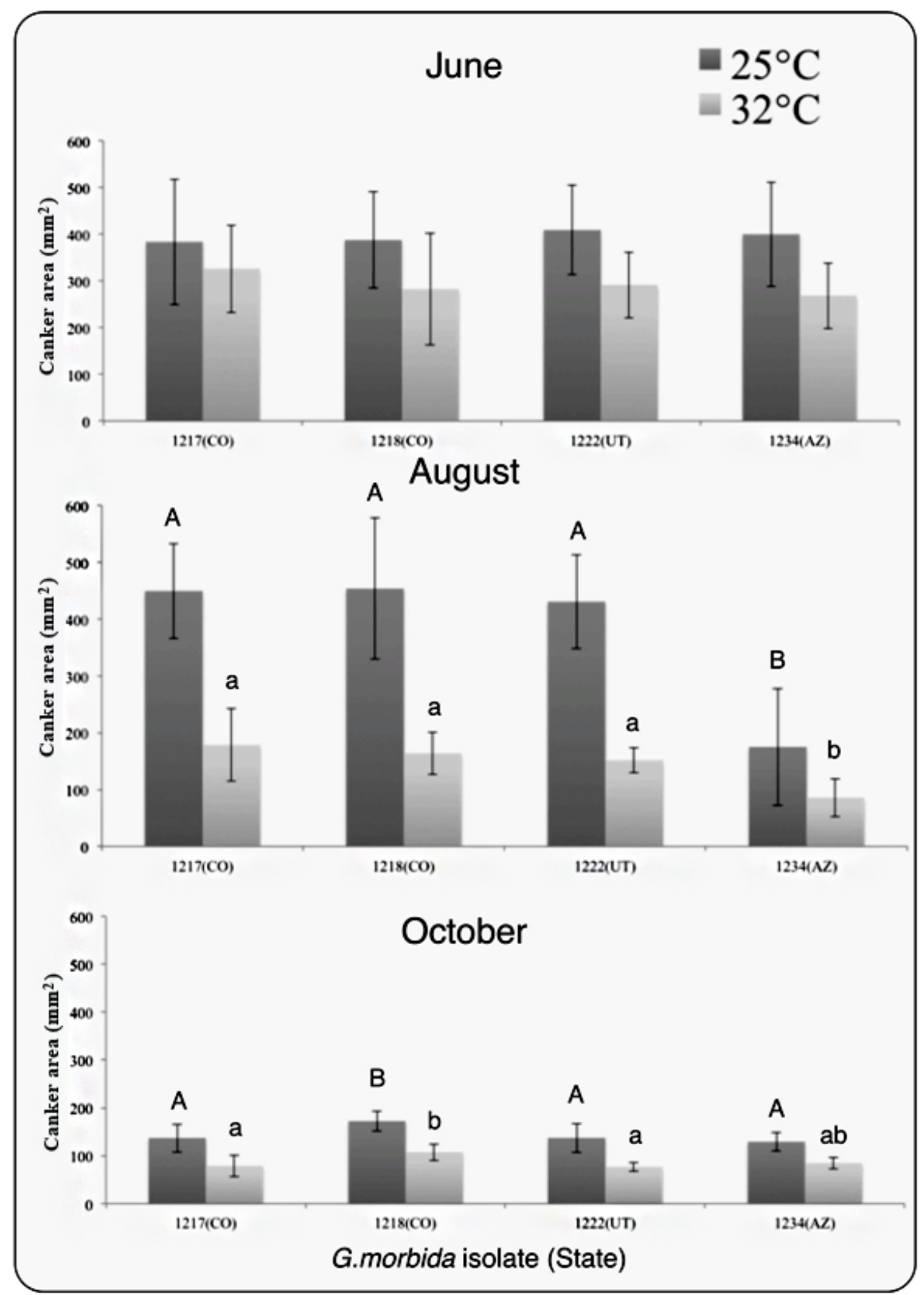

Fig. 4. Average canker area in black walnut trees following inoculation with four Geosmithia morbida isolates representing different rDNA ITS haplotypes at $25 / 20^{\circ} \mathrm{C}$ or $32 / 20^{\circ} \mathrm{C}$ day/night temperatures in May 2010 (family OSU1). The experiment was repeated in August (familyOSU295) and October 2010 (family Green 280).

Temperature differences were significant $(P<0.05)$ for each month. Within each temperature, isolate means not followed by the same letter are different $(P=0.05)$ by Tukey's HSD test. Bars represent standard deviations. 


\section{July 2011}

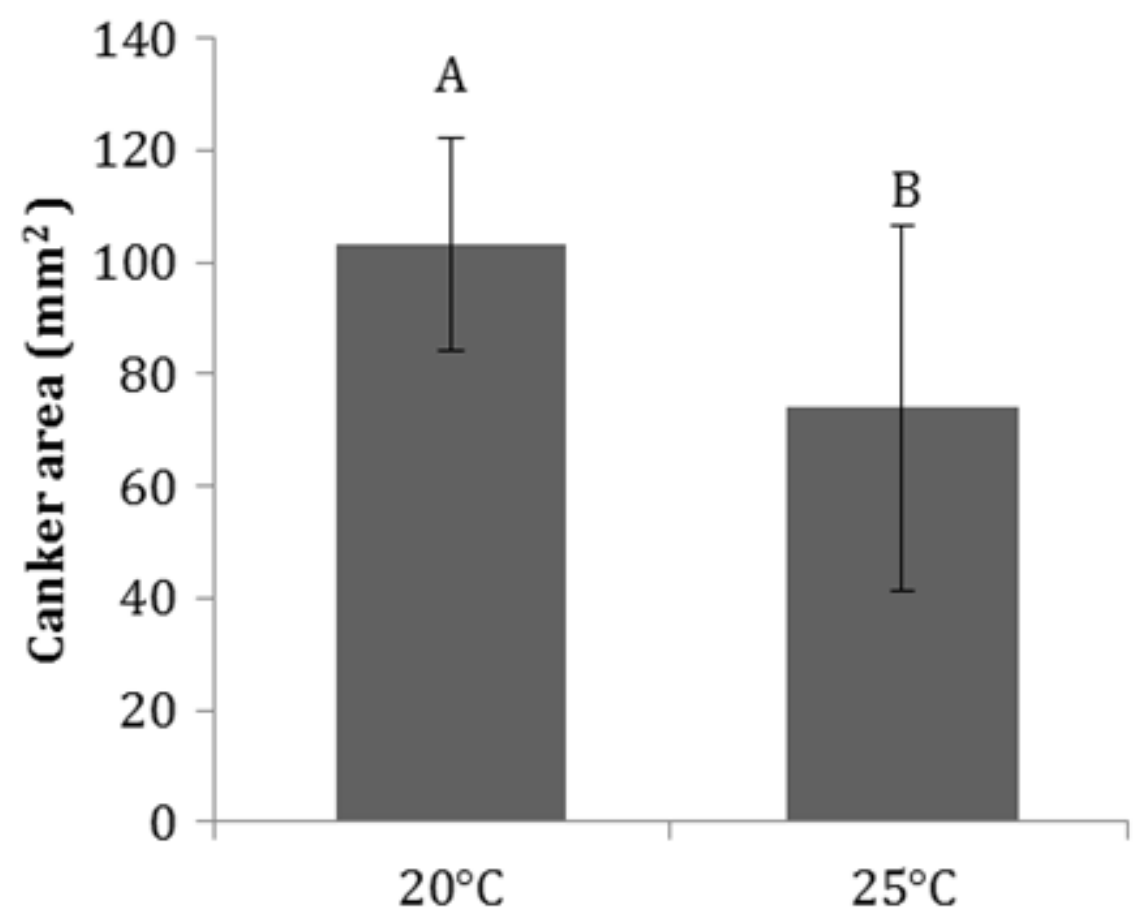

Fig. 5. Average canker area in black walnut trees following inoculation with two Geosmithia morbida isolates (1217 and 1218). Means not followed by the same letter are different $(P=0.05)$ by Tukey's HSD test. Bars represent standard deviations.

\section{Summary}

Cankers were produced in black walnut at every wound following inoculation with $G$ morbida and canker areas were reasonably consistent within treatments. This confirms this inoculation technique provides a reliable method of assessing environmental or genetic effects on canker formation in black walnut. Canker areas were not influenced by position (height) on the stem. Therefore, multiple inoculations on a small, single-stemmed tree can be performed (e.g., with different G. morbida isolates) without influencing canker size. In our experiments, we harvested stems after six weeks to assess canker development but preliminary trials indicated that cankers continued to enlarge after six weeks. Nevertheless, treatment effects could be determined accurately at the shorter time interval, freeing up growth chambers for additional studies. Unfortunately, canker areas could not be accurately determined without first harvesting the stems and removing the outer bark to expose the discolored phloem. This made it impossible to repeat inoculations on the trees having just a single stem. In preliminary experiments, we tried to inoculate sections of detached branches at different temperatures. However, G. morbida quickly colonized the phloem at all temperatures and made treatment comparisons difficult (data not shown).

Neutral markers, such as rDNA ITS haplotypes, have in some cases been shown to correlate with aggressiveness differences in plant pathogens (8). In our study, all G. morbida haplotypes tested were pathogenic to black walnut. In some experiments we observed small differences in aggressiveness among haplotypes. For example, isolate 1234, representing rDNA ITS haplotype group7 that has only been collected from Arizona walnut in Arizona, was slightly less aggressive than some isolates from haplotype groups collected from black walnut in Colorado. Isolates 1217 and 1274 belong to haplotype group 1, the most frequently isolated ITS haplotype isolated from black walnut and its hybrids throughout the western United States (3). Yet these isolates were not consistently more aggressive than isolates from other haplotypes. Thus, the 
frequency of ITS haplotype group 1 in the G. morbida population is probably not directly linked with virulence factors and it is unlikely that a single, highly aggressive haplotype is responsible for the current TCD epidemic.

Surviving black walnuts have been found in areas severely impacted by TCD (e.g., Boulder, $\mathrm{CO}$ ) suggesting that there may be variation in susceptibility to $G$. morbida or WTB (13). Although we found differences in canker areas among black walnut half-sibling families in one experiment, results were inconsistent. This may have been due to the fact that, because of destructive sampling, the exact same trees were not used in replicate experiments. Black walnut is an open pollinated (wind dispersed pollen) species with high genetic diversity and low differentiation among populations (16). Intra-family variability could have masked any maternal influence on canker development, especially with the low number of tree replicates used in these experiments. Furthermore, the black walnut families we used were arbitrarily selected and not chosen based on empirical knowledge of their potential resistance/susceptibility to TCD. Alternatively, inoculations done at different times of the year and likely at different physiological conditions of the tree may have affected canker development, as evidenced by the overall smaller canker areas we observed on certain dates. In any case, further screening of surviving black walnuts, as well as half-sibling walnuts selected for improved nut or timber qualities to $G$. morbida is needed.

Cankers formed in black walnut trees at all temperatures tested, but they were consistently smaller when trees were incubated at $32 / 20^{\circ} \mathrm{C}$ day/night temperatures. This is surprising considering G. morbida is thermotolerant and is apparently native to the southwestern United States where summer temperatures can be extreme. We also assumed that higher temperatures would stress black walnut trees that are adapted to more northern and cooler regions of the United States. High temperatures have been shown to predispose certain trees to cankers (17). Instead we conclude that prevailing temperatures during the growing season of black walnut in its native range will be conducive to bark colonization by G. morbida.

\section{Acknowledgments}

We thank the USDA NIFA Western Region IPM Center and Critical IssuesEmerging and New Plant and Animal Pests and Diseases grant programs and the USDA Forest Service Forest for their financial support of this work. We also thank Jim McKenna for supplying black walnut trees for this experiment, and C. Utley, R. Feild, M. Shenk, and L. Holder for their technical support.

\section{Literature Cited}

1. Abramoff, M. D., Magelhaes, P. J., and Ram, S. 2004. Image processing with ImageJ. Biophotonics Int. 11:36-42.

2. Blackman, M. W. 1928. The genus Pityophthorus Eichh. in North America: A revisional study of the Pityophthorini, with descriptions of two new genera and seventy-one new species. Bull. N.Y. St. Coll. For. 1(3-6).

3. Freeland. E. 2012. Intraspecific variability of Geosmithia morbida, the causal agent of thousand cankers disease, and effects of temperature, isolate and host family (Juglans nigra) on canker development. M.S. thesis. Colorado State Univ., Ft. Collins, CO.

4. Grant, J. F., Windham, M. T., Haun, W. G., Wiggins, G. J., and Lambdin, P. L. 2011. Initial assessment of thousand cankers disease on black walnut, Juglans nigra, in eastern Tennessee. Forests 2:741-748.

5. Haun, G., Powell, S., Strohmeier, C., and Kirksey, J. 2010. State of Tennessee Thousand Cankers Disease Action Plan, October 25, 2010. Online. Tennessee Dept. of Agric., Ellington Agric. Center, Nashville, TN.

6. Kolař́k, M., Freeland, E., Utley, C., and Tisserat, N. 2011. Geosmithia morbida sp. nov. a new phytopathogenic species living in symbiosis with the walnut twig beetle (Pityophthorus juglandis) on Juglans in the USA. Mycologia 103:325-332.

7. Mahuku, G. S., and Riascos, J. J. 2004. Virulence and molecular diversity within Colletotrichum lindemuthianum isolates from Andean and Mesoamerican bean varieties and regions. Eur. J. Plant Path. 110:253-263. 
8. Pascual, C. B., Toda, T., Raymondo, A. D., and Hyakumachi, M. 2000. Characterization by conventional techniques and PCR of Rhizoctonia solani isolates causing banded leaf sheath blight in maize. Plant Path. 49:108-118.

9. Pennsylvania Department of Agriculture. 2011. Agriculture department announces detection of thousand cankers disease in Pennsylvania trees, enacts quarantine to prevent spread retrieved. Online (Press released reproduced by PR Newsire, New York, NY). Pennsylvania Dept. of Agric., Harrisburg, PA.

10. Seybold, S. J., Haugen, D., O’Brien, J., and Graves, A. 2010. Pest Alert: Thousand Cankers Disease. USDA Forest Service, Northeastern Area, State and Private Forestry, Newtown Square, PA.

11. Sugimoto, M. 2003. Genetic, morphological, and virulence characterization of the entomopathogenic fungus Verticillium lecanii. J. Invert. Path. 82:176-187.

12. Tisserat, N., Cranshaw, W., Leatherman, D., Utley, C., and Alexander, K. 2009. Black walnut mortality in Colorado caused by the walnut twig beetle and thousand cankers disease. Online. Plant Health Progress doi:10.1094/PHP-2009-0811-01RS.

13. Tisserat, N., Cranshaw, W., Putnam, M. L., Pscheidt, J., Leslie, C. A., Murray, M., Hoffman, J., Barkley, Y., Alexander, K., and Seybold, S. J. 2011. Thousand cankers disease is widespread in black walnut in the western United States. Online. Plant Health Progress doi:10.1094/PHP-2011-0630-01-BR.

14. Utley, C., Cranshaw, W., Seybold, S., Graves, A., Leslie, C., Jacobi, W., and Tisserat, N. 2009. Susceptibility of Juglans and Carya species to Geosmithia: A cause of thousand cankers disease. Phytopathology 99:S133.

15. VDACS. 2011. Thousand Cankers Disease. Online. Virginia Dept. of Agric. and Consumer Serv. (VDACS), Richmond, VA.

16. Victory, E. R., Glaubitz, J. C., Rhodes, Jr., O. E., and Woeste, K. E. 2006. Genetic homogeneity in Juglans nigra (Juglandaceae) at nuclear microsatellites. Am. J. Bot. 93:118-126.

17. Worrall, J. J., Adams, G., and Tharp, S. C. 2010. Summer heat and an epidemic of cytospora canker of Alnus. Can. J. Plant Path. 32:376-386. 